Article

\title{
The Effectiveness of the Application of a Chemical Agent (Dressing) to Seed Potatoes by Means of an Innovative Valve Enabling Intermittent Flow of a Liquid
}

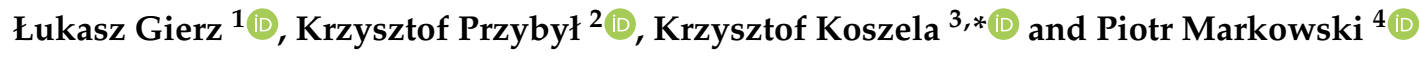 \\ 1 Faculty of Transport Engineering, Poznan University of Technology, Piotrowo 3, 60-965 Poznan, Poland; \\ lukasz.gierz@put.poznan.pl \\ 2 Institute of Food Technology of Plant Origin, Faculty of Food Sciences and Nutrition, \\ Poznan University of Life Sciences, Wojska Polskiego 31, 60-624 Poznan, Poland; kprzybyl@up.poznan.pl \\ 3 Institute of Biosystems Engineering, Poznan University of Life Sciences, Wojska Polskiego 50, \\ 60-625 Poznan, Poland \\ 4 Department of Heavy-Duty Machines and Research Methodology, University of Warmia and Mazury, \\ Oczapowskiego 11, 10-719 Olsztyn, Poland; pitermar@uwm.edu.pl \\ * Correspondence: koszela@up.poznan.pl; Tel.: +48-502-288-097
}

Received: 28 February 2020; Accepted: 15 March 2020; Published: 19 March 2020

\begin{abstract}
The protection of potatoes from pests and diseases, especially at an early stage of their development, is an indispensable element of cultivation. Pesticides are most commonly used for protection, but their high doses may adversely affect the natural environment, including soil and water. This study compares the losses of a chemical agent emitted during the dressing of seed potatoes by means of an innovative valve enabling intermittent outflow of the liquid and by means of a standard valve with a continuous outflow. The research proved that the intermittent outflow of the working liquid decreased the amount of the chemical agent emitted into the environment ten times. The article also describes the site at which the innovative valve was tested and compares the results of laboratory tests for three distances of the sprayer from the potato fall path $(50,100$, $150 \mathrm{~mm}$ ) and four different pressures of the working liquid $(1-4 \mathrm{kPa})$. The research showed that the amount of losses, i.e., emissions of the chemical agent into the environment from the innovative valve (intermittent stream of the working liquid) depended on the difference in the air and liquid pressure. The solution is environmentally friendly. The results showed that the distance between the sprayer valve and the seed potato falling path had minimal influence on the amount of the agent left on the surface of seed potatoes when a continuous stream was applied, but it had considerable influence when an intermittent stream was applied. The distance had negative effect on the ratio of retention of the applied liquid at pressures of 100 and $200 \mathrm{kPa}$, but it had positive effect at pressures of 300 and $400 \mathrm{kPa}$ (at an intermittent flow). When a continuous stream was applied and the distance between the spray valve and the seed potato falling path increased from 100 to $150 \mathrm{~mm}$, it had positive effect on the retention coefficient for all the four pressures tested $(100,200,300,400 \mathrm{kPa})$.
\end{abstract}

Keywords: potato; intermittent stream of liquid; innovative valve; emission of chemical agent; weight method

\section{Introduction}

Potatoes (Latin: Solanum tuberosum) are some of the most popular root crops all over the world [1-3]. The consumption of products made from edible potatoes (fried products—crisps and chips, frozen, 
preserved and ready-to-eat products—dumplings, pancakes, etc. and dried raw or boiled potatoes) is continuously increasing in Poland and around the world [4]. Food processing and industrial processing are two of the three sectors where potatoes are used [5,6]. In the previous season $49 \%$ of the total volume of potatoes processed in these sectors was used for starch production.

Potatoes are also a source of cheap food because of their high nutritional value and yield [7]. Therefore, they can compete with wheat and rice in Asia [8]. In view of the high market for potato tubers for direct consumption they should be characterised by adequate external features such as: average size, regular shape, shallow eyes, adequate colour of the peel and flesh (no greening), the condition of the tuber surface (appropriate texture without cracks), no mechanical (transport) damage $[9,10]$. The following internal features are also important: high taste values, no darkening of raw or cooked potatoes, appropriate consumption- and usability-related features (the firmness, flouriness, delicacy and structure of the flesh) and the right content of starch (potato cultivars for industrial purposes) [11,12]. The high yield of a cultivar is a particularly important factor for the producer. This involves appropriate agrotechnical and crop protection procedures, which may vary in different parts of the world $[13,14]$.

When consumers in Poland and other countries all over the world buy vegetables, including potatoes, they are more and more often concerned not only about the appearance of these products but also their content of chemicals, which is important for health [15]. In 2014 the principles of integrated pest management (IPM) were introduced to agricultural production, which allows the use of all crop protection methods [16] and minimises the risk to humans, animals and the environment $[17,18]$. At present most European countries promote ecological aspects and try to take care of the natural environment $[19,20]$. The 'Ecophyto 2018' programme was introduced with due consideration of the environmental risks in order to reduce the use of crop protection products during production to $50 \%$ [21]. The programme allowed for various aspects of crop protection products used for agricultural production, including the production of potatoes. Crop protection products are important elements of cultivation due to the safety of the natural environment, groundwater and human health [22]. Spraying chemicals is a crop protection method applied to seed potatoes. This treatment should be carried out precisely [23]. In Poland dressings are usually applied to potato tubers by means of stationary dressing machines located in seed potato warehouses. As treatment with these devices is laborious, it takes more time to prepare seed potatoes for planting. In addition, potato tubers are not placed in the soil immediately after the treatment. It seems more reasonable to dress potatoes with devices mounted on transplanters or tractors, which directly apply the required layer of dressing to seed potato tubers during planting. The solutions which are currently used to dress seed potatoes in devices such as GRIMME are still very expensive. This significantly hinders the development of the future crop protection technology. Therefore, it is necessary to make an optimal selection of various magnitudes and parameters in order to ensure normal operation of the dressing device. This enforces development towards precision agriculture [24,25]. Zimny (2007) defines precision agriculture as the use of information technology to match input doses of fertilisers and crop protection products to the potential demand of the crop grown. The process requires measurement of soil properties, the distribution of weeds and the development of diseases and pests in individual parts of the field [26]. This changes the traditional approach to agriculture because a field is no longer treated as a whole-instead it is divided according to a map showing the soil abundance. In general, precision agriculture can be defined as a set of technological procedures introduced in agriculture to adjust technology to variable soil conditions in individual parts of the field [27-29]. The implementation of the principles of precision agriculture is more profitable in large fields, which are characterised by considerable variability of soil abundance parameters. In practice, the postulates of precision agriculture are met by individual treatment of individual parts of the field and by the use of modern machinery $[30,31]$. Most machines are equipped with electronic and automatic systems, which improve their efficiency and accuracy. The advantages of precise agriculture can be related to economic functions (lower labour costs, shorter agrotechnical treatment time, optimal use of the farm area) and ecological 
functions (precise use of chemicals reduces the amount of these substances that needs to be applied in a given plantation) [32]:

The first symptoms and attempts to use precision agriculture date back to the 1980s. This technology began to develop rapidly in the 1990s, when the Global Positioning System (GPS) developed. This technology solved the problem of positioning machines in a field, enabled the creation of a map of the soil abundance in a plantation and adaptation of the parameters of machinery to individual parts of the field area [33,34]. Owing to the information and communication technology, the construction of modern machinery precision agriculture is developing faster [35].

Currently planters are equipped with dressers applying the working liquid in a continuous flow, e.g., Grimme or ApliTech. When potatoes are being planted one at a time, there are undesirable emissions of chemicals to the environment. If potatoes are planted at intervals, chemicals can also be dosed at intervals in an intermittent outflow of the working liquid. Therefore, following the requirements of precision agriculture and strictly defined ecological standards specified in the 'Ecophyto2018' programme, the authors of this article designed and constructed an electronically controlled valve with an auxiliary air stream in a mobile potato dresser mounted in a potato planter. The aim of the study is to assess the amount of the chemical lost (emitted to the environment) in an intermittent flow (innovative valve) and a continuous flow of the dressing liquid. In addition, the amount of the agent left on the peel of seed potatoes was compared for the intermittent and continuous flow of the dressing liquid. The retention coefficient $R$ was proposed for this purpose to assess the amount of the chemical agent left on potatoes in relation to the total amount of the agent used for the intermittent and continuous flow the dressing liquid.

\section{Materials and Methods}

There were two stages of laboratory investigations. At the first stage 100 potato tubers were randomly selected from a group of tubers intended for actual tests (the second stage). The amount of the agent (weight of the dressing agent) which may remain on the surface (peel) of seed potatoes was assessed. The amount (weight) of the dressing agent left on the tuber surface was calculated as the difference in the weight of the tuber after and before its immersion in water. The weight was measured on a RADWAG PS 1000/Y electronic scale with a measuring accuracy of $0.001 \mathrm{~g}$. At this stage of the research the assumption was that the results would be the reference point for the amount of the agent applied to the tubers at the second stage of the investigations. There were two variants: one with a standard valve and the other with an innovative (original) valve for applying the dressing agent to potato tubers while they were being planted (Figure 1). The research station was used as the basis to construct and patent a prototype of electronically controlled mobile wet dresser (PL 226004) [36]. During the preliminary and actual tests water was used as the working substance (dressing agent), because of the safety of the people making measurements. The physical properties of water are similar to the chemical solution of the dressing agent.

The amount of the chemical agent applied to the seed potatoes (at the second stage) was measured at the designed research station (Figure 1). Ten seed potatoes were placed on the conveyor belt (1) and transported to the spraying chamber (2). The tubers fell vertically through a guiding pipe (3), which was $300 \mathrm{~mm}$ long, with a diameter of $60 \mathrm{~mm}$. Next, the free falling seed potato tubers crossed (obscured) a beam of infrared light emitted by an optical sensor (4). They were sprayed with the dressing agent applied by innovative solenoid valves (PL 224859) [37] (5) equipped with an ARAG TFA ASJ ejection sprayer nozzle at a rate of $0.48 \mathrm{~L} / \mathrm{min}$. There were four solenoid valves in the spraying chamber to ensure better accuracy of covering potato tubers with the dressing agent. The design of the spray chamber (2) and the electronic system controlling the station (6) allowed spraying the seed potatoes like in real field conditions. The patented controller (PL 223195) [38] (Figure 2) allowed setting any delay and switch-on time. In our tests the switch-on delay of the solenoid valves was set at $65 \mathrm{~ms}$, whereas the switch-on time of the solenoid valves-the emission of the chemical agent was set at $80 \mathrm{~ms}$. The values of these times were determined experimentally. The station was equipped with an electric 
pump of the working liquid, which enabled a pressure of up to $800 \mathrm{kPa}(7)$, a valve controlling the working fluid pressure within 0 to $1000 \mathrm{kPa}(8)$, an air pressure reduction valve within 0 to $800 \mathrm{kPa}(9)$, a 120-litre tank for the working fluid (10) and a working fluid pressure gauge (11). The sprayed potato tubers fell into a container (12) under the spray chamber (2). The next step involved measuring the amount (weight) of the dressing agent left on the surface of seed potatoes by calculating the difference in the weight of seed potato tubers after and before the dressing agent was applied.

The retention ratio $\mathrm{R}$ - an indicator defined as the ratio between the mass of the dressing left on potatoes $M_{S}$ and the total amount of the dressing, i.e., the sum of the dressing left on potatoes $M_{S}$ and the mass of dressing lost $\mathrm{M}_{\mathrm{zs}}$, was introduced for the purpose of this study (Equation (1)). It is necessary to pay attention to the mass of dressing lost, because it is emitted into the soil.

$$
R=\frac{M_{s}}{M_{s}+M_{z s}} \cdot 100 \%
$$

where:

$R$-retention ratio,

$M_{s}$-mass of water left on seed potatoes,

$M_{z s}$-mass of water lost (collected in the spray chamber).

The design and construction of the spray chamber enables collection of the liquid which did not remain on the surface of seed potatoes. The liquid is collected in a separate vessel and weighed on the RADWAG PS 1000/Y balance with an accuracy of $0.001 \mathrm{~g}$. The design of the laboratory test enables precise assessment of the mass of the liquid left on potatoes and the mass of losses. Thus, the retention ratio $\mathrm{R}$ can be calculated.

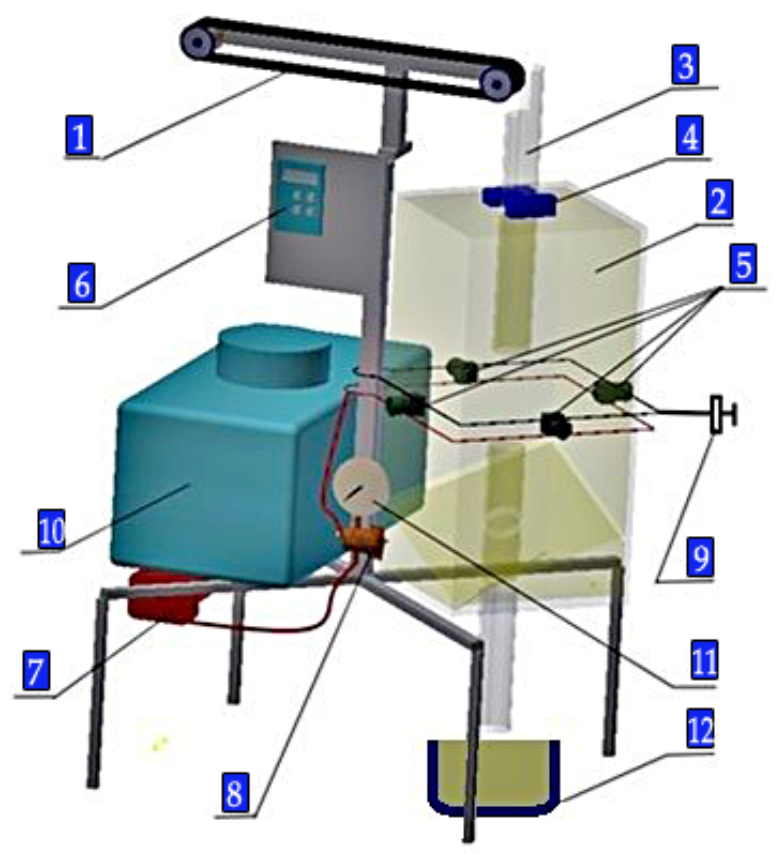

Figure 1. A laboratory facility for assessment of the degree of coverage by means of the weight method: 1-conveyor belt, 2-dressing (spray) chamber, 3-guide channel, 4-optical sensor, 5-innovative solenoid valves, 6-electronic control system, 7-working liquid pump, 8-working liquid pressure control valve, 9-air pressure reducing valve, 10-working liquid tank, 11-working liquid pressure gauge, 12-potato tuber container.

A control device (6) was specially designed to control the test facility. The delay of the switching on time of the solenoid valves and the duration of the solenoid valves switching on time are freely programmable in the control device. 


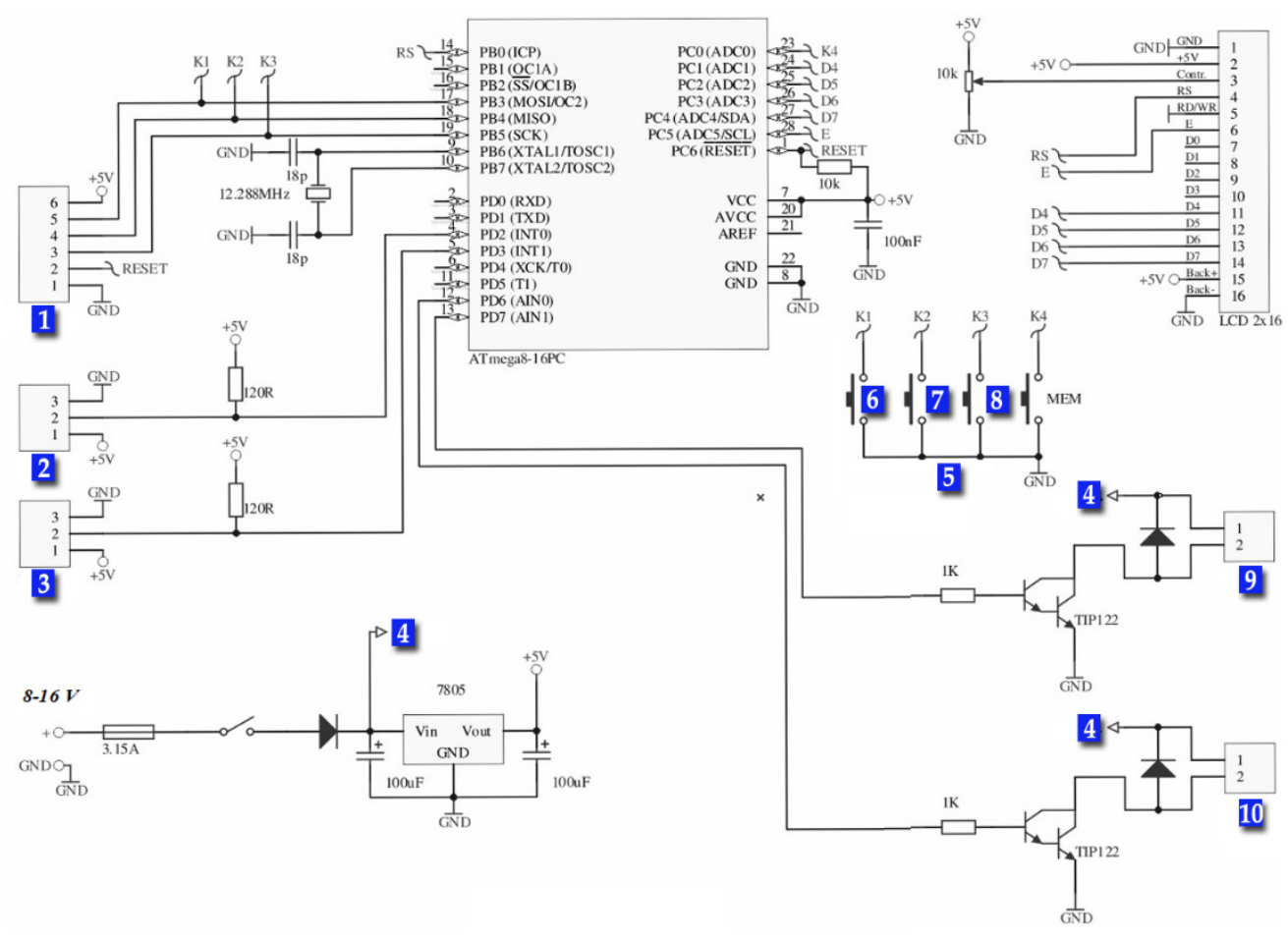

Figure 2. A diagram of the controller used in the test facility (PL 223195): 1-Programmer, 2-Sensor 1, 3-Sensor 2, 4-Valves, 5-Terminal keyboard, 6-Up, 7-Down, 8-Further, 9-Valve 2, 10-Valve 2.

The tests were conducted at a constant temperature $(T)$ of $25.4{ }^{\circ} \mathrm{C}$ and relative humidity $(W)$ of $45 \%$. Throughout the experiment the air parameters were monitored with a Benetech GM9 thermohygrometer with the temperature and humidity measurement accuracy up to $0.5^{\circ} \mathrm{C}$ and $2 \%$, respectively. The constant air temperature and humidity resulted in a similar time of evaporation of water (the working liquid) from the surface of potato tubers.

The variable parameters were:

- $\quad$ The distance between the sprayer nozzles and the axis of the potato tuber falling path $S: 50,100$ and $150 \mathrm{~mm}$;

- $\quad$ The working fluid pressure $p: 100,200,300$ and $400 \mathrm{kPa}$;

- The variant of emission of the spray liquid from the solenoid valve: continuous and intermittent.

The results of measurements of the amount of the agent applied to the surface of potato tubers were analysed statistically, including multivariate analysis of variance (MANOVA). According to the null hypothesis assumed in the research, the groups under analysis did not differ in the amount of the agent applied to the surface of potato tubers depending on the variable factors. The Statistica package v.13 PL was used for the statistical analysis. The level of significance used in the analysis and inference was $\alpha=0.05$.

\section{Results}

Table 1 shows the statistical characteristics of the weight of the potato tubers used in the tests before and after immersion in the working liquid and the amount (weight) of the chemical agent left on the surface of the seed potato tubers after total immersion in the liquid (the reference test). The average weight of the potato tubers before and after immersion in the working liquid amounted to $51.02 \pm 13.66 \mathrm{~g}$ and $51.63 \pm 13.76 \mathrm{~g}$, respectively. The average weight of the working liquid (the dressing agent) left on the surface of the potato tubers was $0.62 \pm 0.13 \mathrm{~g}$. 
Table 1. The statistical characteristics of the potato tuber weight before and after immersion in the working liquid and the weight of the working liquid on the potato tubers (the first stage of the tests).

\begin{tabular}{lccc}
\hline \multirow{2}{*}{ Parameter } & \multicolumn{2}{c}{ Potato Tuber Weight $(\mathrm{g})$} & \multirow{2}{*}{ Weight of Liquid on Surface of Potato Tubers $\mathbf{M c}(\mathbf{g})$} \\
\cline { 2 - 3 } & Before Immersion $\boldsymbol{M} \boldsymbol{b}$ & After Immersion & \\
\hline Minimum & 24.168 & 24.567 & 0.351 \\
Maximum & 90.142 & 91.010 & 0.870 \\
Average & 51.018 & 51.633 & 0.615 \\
Median & 49.439 & 50.008 & 0.607 \\
Standard deviation & 13.664 & 13.763 & 0.128 \\
Coefficient of variation (\%) & 26.782 & 26.656 & 20.753 \\
\hline
\end{tabular}

Figure 3 shows a second-degree equation describing the amount of the chemical agent covering the surface (epidermis) of potato tubers depending on their weight (the reference test). The equation is characterised by good fit to the empirical data. The value of the correlation coefficient was 0.79 .

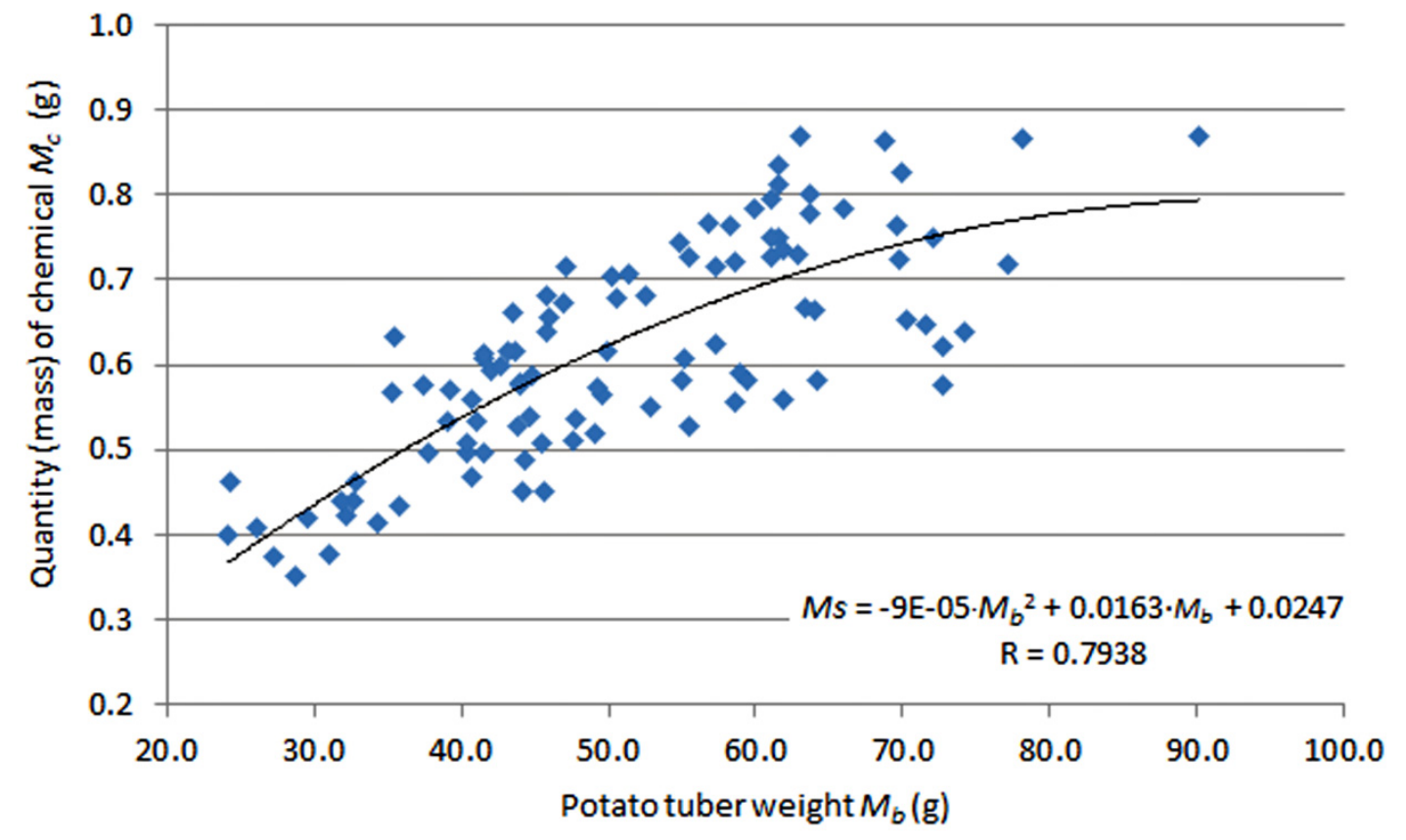

Figure 3. The dependence between the amount of the agent applied to the surface of seed potato tubers and the tuber weight.

In the next stage the effect of the electronically controlled sprayer valve was compared with the steady flow of the working liquid (Figures 4 and 5) and the electronically controlled valve with an intermittent flow of the working liquid (Figures 6 and 7).

Figure 4 shows the amount of the chemical agent left on the surface of the seed potato subjected to the dressing process. The retention ratio was also calculated for the constant flow of the liquid from the sprayer (Figure 5). The amount of the agent left on the seed potato surface and the retention ratio increased along with the working liquid pressure. The largest amount of the chemical agent was applied at a distance of $150 \mathrm{~mm}$ and working pressure of $400 \mathrm{kPa}$ (Figure 4). The results show that as the distance between the sprayer and the potato falling path increased, so did the amount of the agent left on the seed potato surface at each pressure, assuming that the ambient parameters, such as the air temperature and relative humidity were constant. 


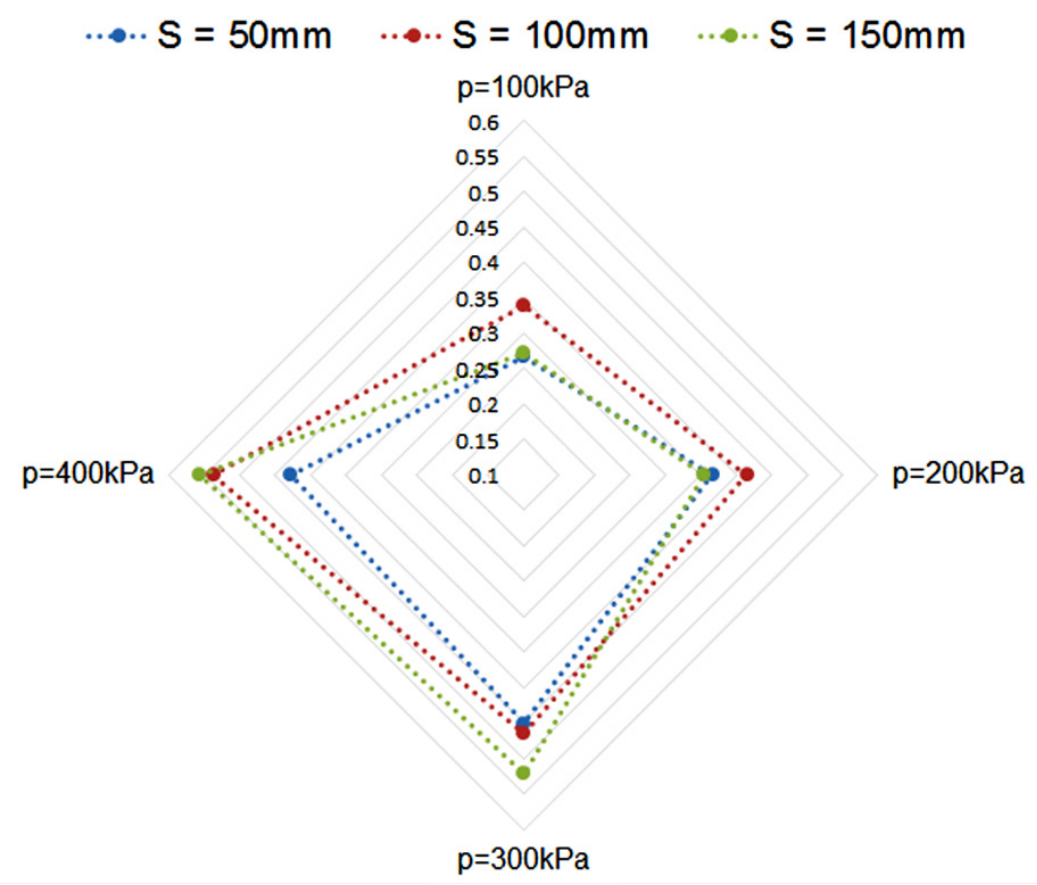

Figure 4. The amount of the chemical agent $(\mathrm{g})$ on the seed potato surface for the valve without electronic control, depending on the falling path distance $(\mathrm{mm})$ (continuous flow of the liquid).

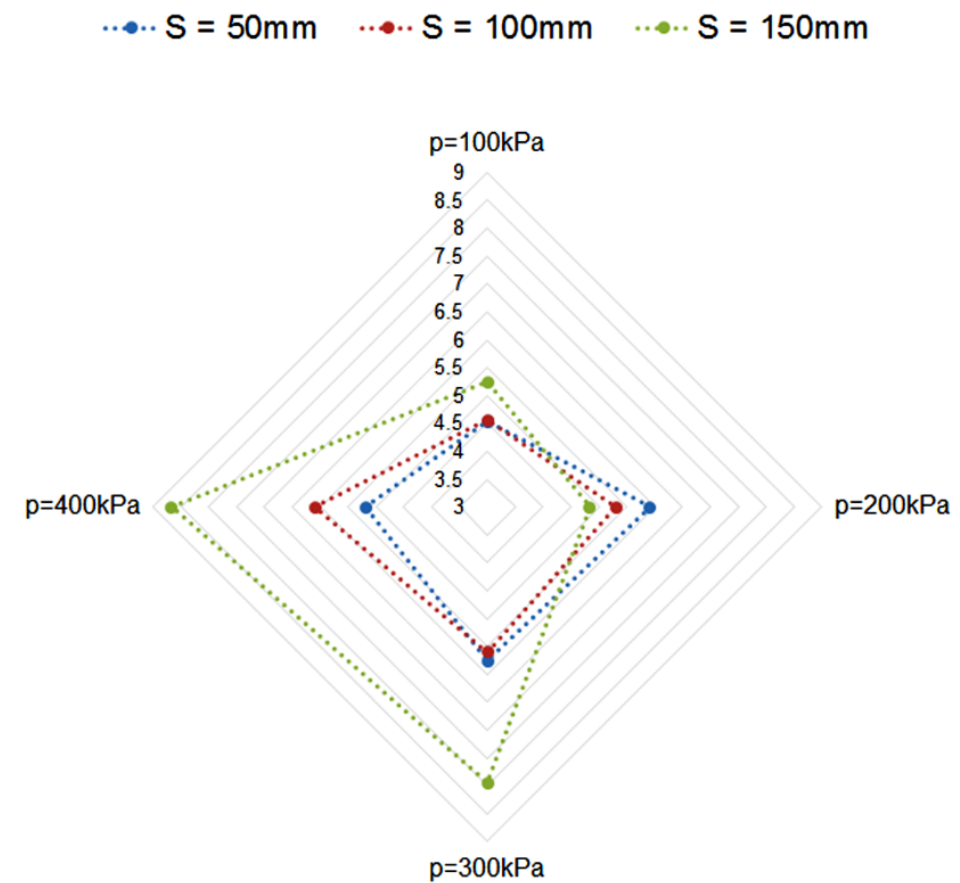

Figure 5. The ratio of retention (\%) of the agent on the seed potato surface for the valve without electronic control, depending on the falling path distance $(\mathrm{mm})$ (continuous flow).

The authors decided to check the influence of an auxiliary airstream in the electronically controlled valve to verify the information in reference publications and their own experience. Figures 6 and 7 show the results of comparative tests checking the influence of the value of the auxiliary airstream pressure, which was successively lowered by $50 \mathrm{kPa}$ in relation to the working liquid pressure. The influence of the distance between the sprayer valve and the seed potato falling path as well as the influence of the working liquid pressure varying within $100-400 \mathrm{kPa}$ was tested for the pressure values. 


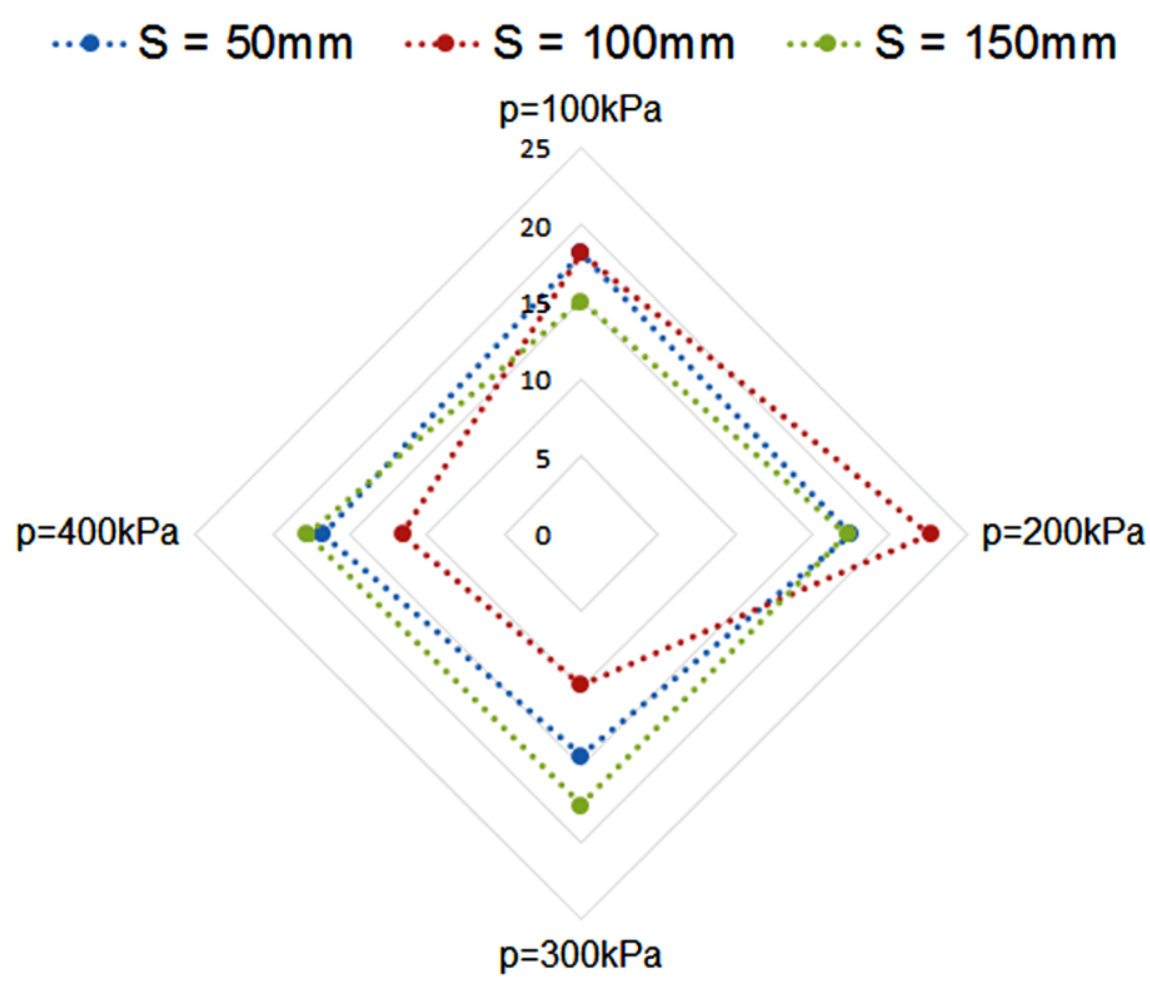

Figure 6. The amount of the chemical agent (g) on the seed potato surface for the electronically controlled valve, depending on the falling path distance $(\mathrm{mm})$ (air pressure reduced by $50 \mathrm{kPa}$ ).

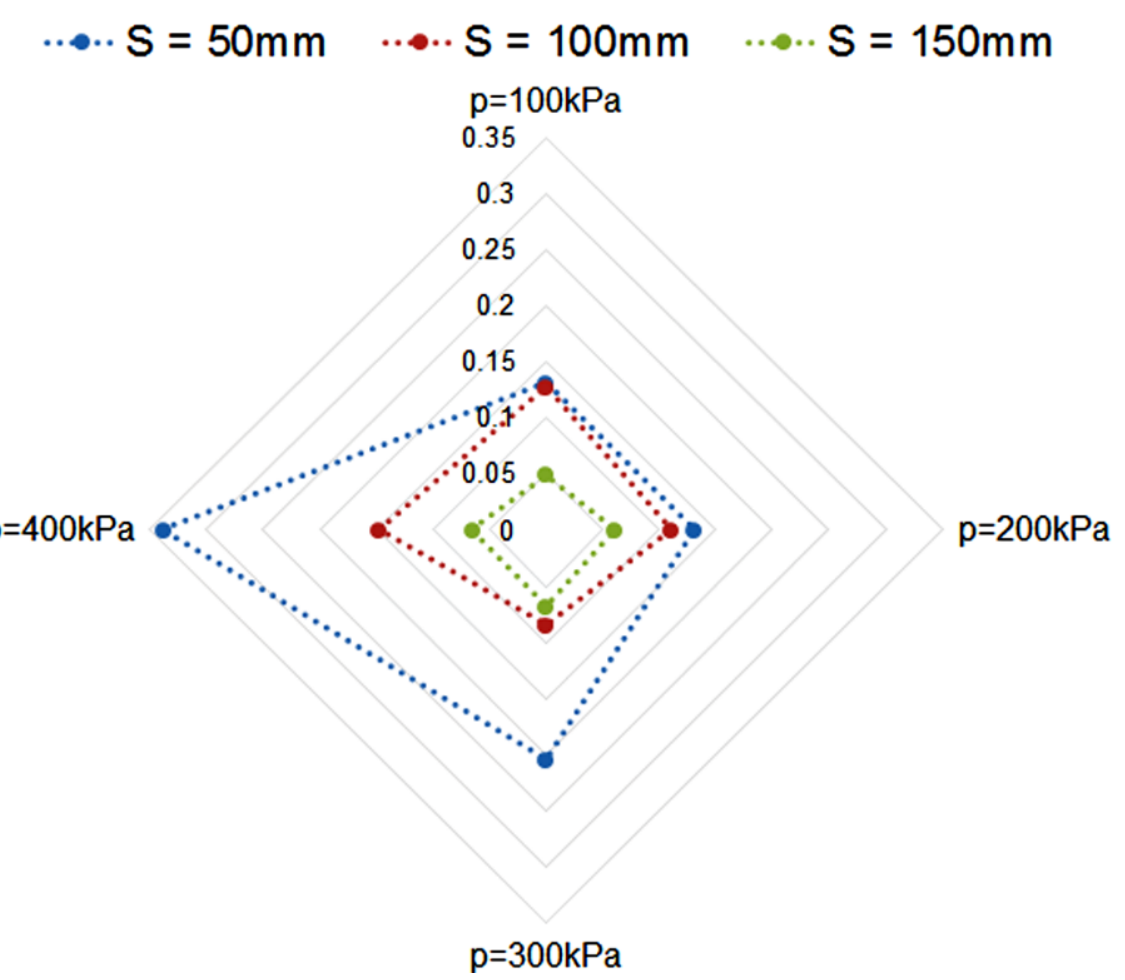

Figure 7. The ratio of retention (\%) of the chemical agent on the seed potato surface for the electronically controlled valve, depending on the falling path distance $(\mathrm{mm})$ (air pressure reduced by $50 \mathrm{kPa}$ ).

\section{Discussion}

The laboratory investigations provided a considerable set of data, which confirmed the dependence between the amount and the ratio of retention $(\mathrm{R})$ of the chemical agent remaining on the seed potato 
surface after the dressing process. The amount (weight) of the working liquid measured on the surface of potato tubers (seed potatoes) at the first stage of the tests after immersion of the tubers in water was used as a reference point for the results of the amount of the agent applied to the tubers at the second stage of the tests. When the seed potatoes were immersed in water, the average amount of the dressing per seed potato was $0.62 \mathrm{~g}$ (Table 1). However, when an intermittent outflow of the liquid with an auxiliary airstream was applied, on average there was $0.35 \mathrm{~g}$ of the liquid per seed potato (Figure 7). During the continuous outflow of the liquid from the sprayer, when the nozzle was positioned at a distance of $50 \mathrm{~mm}$ from potatoes and the working liquid pressure was $400 \mathrm{kPa}$, the average amount of the agent covering the potato surface was $0.4 \mathrm{~g}$ (Figure 4). Bayer CropScience recommends the following amount of Prestige Forte 370 dressing to be applied: $0.8-1.5$ litres of the solution per $100 \mathrm{~kg}$ of potatoes. If we assume that the average weight of one potato is $50 \mathrm{~g}$, the amount of the agent applied ranges from 0.4 to $0.75 \mathrm{~g}$. Thus, the amount of the liquid used in the tests was sufficient and it should ensure proper protection of potato plants from diseases and pests.

The degree of retention of the working fluid was also analysed. As the results showed, the degree of retention depended on the distance between the sprayer and the axis of the potato falling pathway and on the value of the working pressure. When there was a greater distance from the axis of the potato tuber falling path, a greater amount of the agent was applied to the surface of seed potatoes. This dependency was observed at each of the pressures used in the tests, assuming that there was constant ambient air temperature and relative humidity. This information is important to choose the location of the spraying nozzle in relation to the falling path of potato tubers while being planted, because they can be covered with the chemical agent more thoroughly and thus they can be better protected from viral diseases and pests. The effect of the chemical agent applied evenly and at an appropriate amount to the surface of potatoes was determined by Erlichowski et al. [39]. They conducted experimental research and proved that the chemical agent applied at a dose of $100 \mathrm{~mL} / 100 \mathrm{~kg}$ ) influenced the effectiveness of protection of the potato plantation from pests [39].

The experiment showed that after immersing seed potatoes in the chemical agent, the amount left on the surface of the potatoes corresponded to the minimum dose of the chemical agent for seed materials proposed by manufacturers of chemicals. The amount of the agent left on the surface of seed potatoes after spraying them with the working liquid applied in a continuous flow was comparable with the amount of the agent applied to seed potatoes by immersion, i.e., about $0.6 \mathrm{~g}$ per potato.

The second area of the analysis involved measurements of the amount of the agent lost during the application of the working liquid to seed potatoes. The test results clearly indicate that electronically controlled valves with an intermittent flow of the liquid from the nozzle with an auxiliary air stream had beneficial effect at all the four pressures $(100,200,300,400 \mathrm{kPa})$. When the liquid was sprayed with a continuous flow, $85 \mathrm{~g}$ of the lost liquid was used for a sample of 10 seed potatoes at a pressure of $400 \mathrm{kPa}$ (Figure 8). However, when the electronically controlled valve with an auxiliary airstream was used, the amount of the chemical agent lost was more than five times smaller at a pressure of $400 \mathrm{kPa}$, i.e., $16 \mathrm{~g}$ (Figure 9). Thus, about $80 \%$ of the agent needed for treatment with the liquid was saved, but the quality of the treatment was maintained. The multivariate analysis of variance (MANOVA) showed that all the variables significantly $(\alpha=0.05)$ influenced the amount of the agent applied to the surface (peel) of seed potatoes (Table 2). 


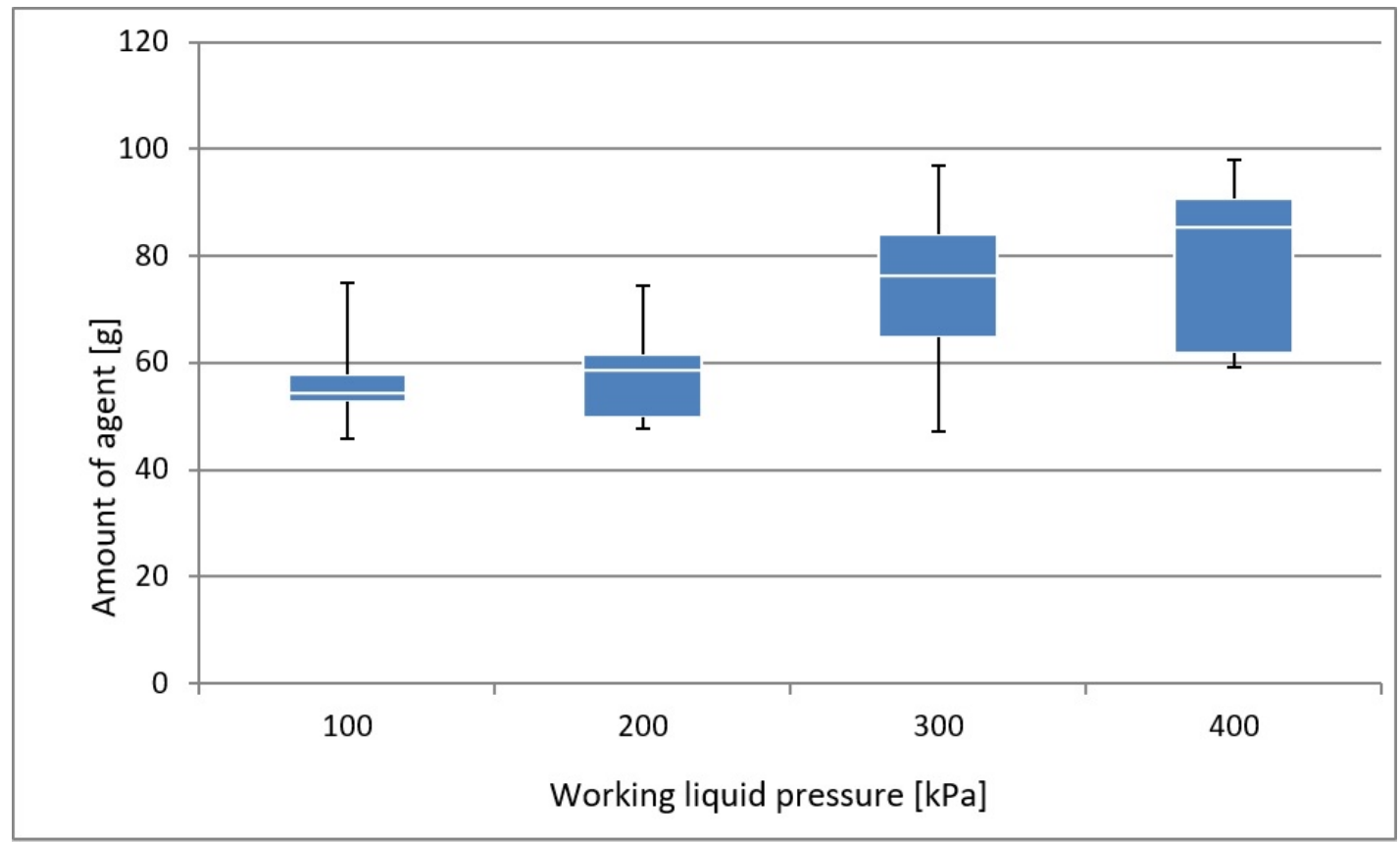

Figure 8. The amount of the agent lost (applied outside the surface of seed potatoes) for a valve without electronic control at a distance of $50 \mathrm{~mm}$ between the valve and the seed potato falling path (continuous stream of the liquid).

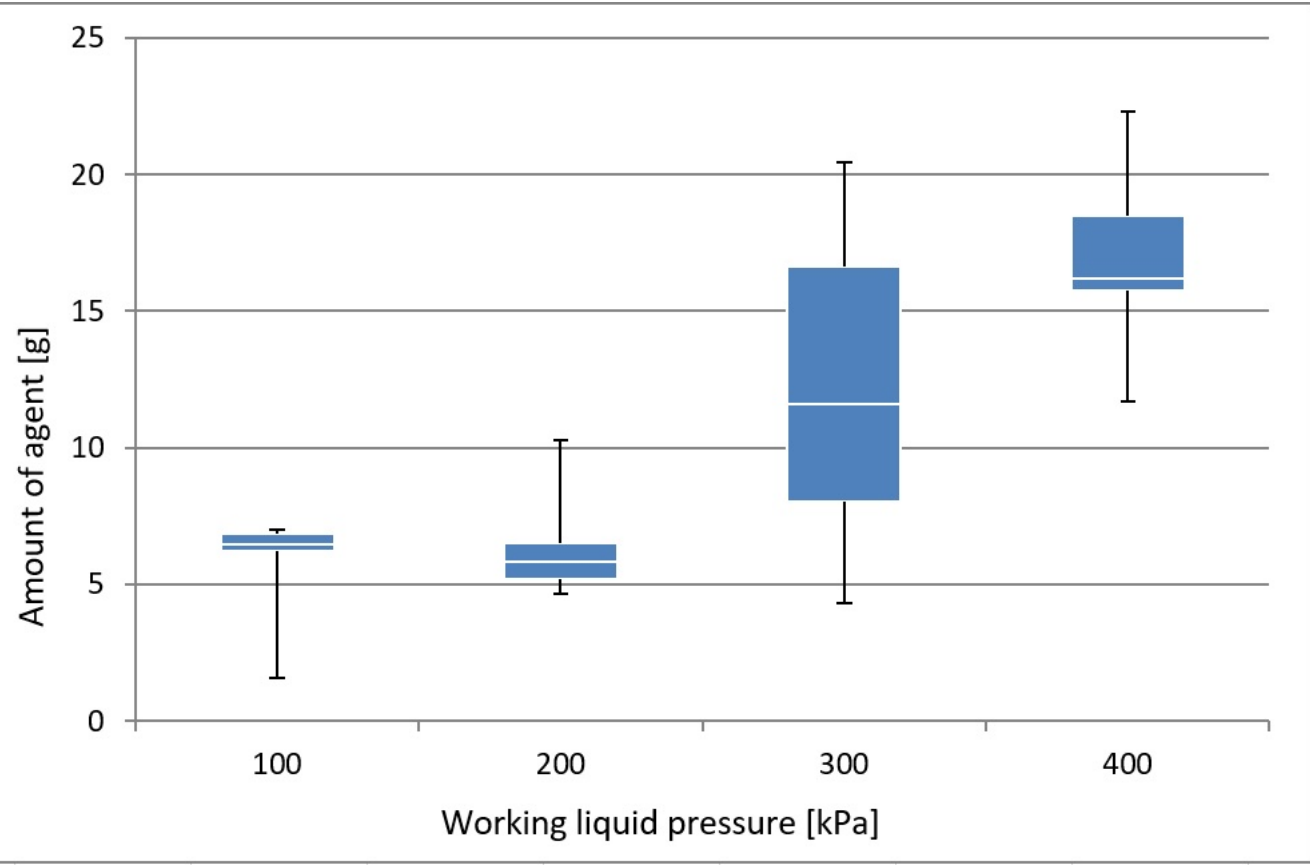

Figure 9. The amount of the agent lost (applied outside the seed potato surface) for the electronically controlled valve for the $50-\mathrm{mm}$ distance between the valve and the seed potato falling path (air pressure reduced by $50 \mathrm{kPa}$-intermittent stream of the liquid). 
Table 2. The results of multivariate analysis of variance (MANOVA) of the adopted parameters vs the amount of the agent applied to the surface of seed potatoes.

\begin{tabular}{|c|c|c|c|c|c|}
\hline \multirow[t]{2}{*}{ Effect } & \multicolumn{5}{|c|}{$\begin{array}{c}\text { Multivariate Tests of Significance for the Amount of Chemical Agent by Weight } \\
\text { Parameterisation Method with Sigma-Limitations } \\
\text { Decomposition of Effective Hypotheses }\end{array}$} \\
\hline & SS & Degrees of Freedom & MS & $\mathbf{F}$ & $p$ \\
\hline $\begin{array}{l}\text { sprayer } \\
\text { distance }\end{array}$ & 4.58 & 2 & 2.29 & 86.07 & 0.00 \\
\hline controlling & 92.43 & 1 & 92.43 & 7729.89 & 0.00 \\
\hline liquid pressure & 7.54 & 3 & 2.51 & 96.22 & 0.00 \\
\hline $\begin{array}{l}\text { auxiliary } \\
\text { airstream }\end{array}$ & 15.92 & 3 & 5.31 & 214.67 & 0.00 \\
\hline
\end{tabular}

The empirical research showed that the retention ratio in all configurations with the electronic valve with an auxiliary airstream was significantly better than in the electronically controlled valve without the airstream. The highest values of the retention ratio were noted when the distance between the sprayer and the seed potato falling path was $50 \mathrm{~mm}$ and the air pressure was $25 \mathrm{kPa}$ lower than the working liquid pressure. When the air pressure was $50 \mathrm{kPa}$ lower than the working liquid pressure, the retention ratio tended to decrease as the difference in the air pressure increased. These results can be explained by the influence of the pressure. Lower air pressure extended the time necessary for the working liquid pressure to rise when the valve was switched on. In consequence, this extended the time of reaction to the valve being switched on and the formation of a proper stream of the liquid sprayed.

\section{Conclusions}

The laboratory tests (the intermittent flow of the liquid) showed that the distance between the sprayer valve and the seed potato falling path had a negative effect on the ratio of retention of the applied liquid at pressures of 100 and $200 \mathrm{kPa}$, but it had a positive effect on the pressures of 300 and $400 \mathrm{kPa}$. When the distance increased from $100 \mathrm{~mm}$ do $150 \mathrm{~mm}$ at a pressure of $200 \mathrm{kPa}$, the retention ratio decreased from $22.6 \%$ to $17.2 \%$. On the other hand, at a pressure of $300 \mathrm{kPa}$ the retention coefficient value increased from $9.7 \%$ to $17.5 \%$. When the continuous outflow was applied and the distance between the sprayer valve and the seed potato falling path increased from $100 \mathrm{~mm}$ to $150 \mathrm{~mm}$, it had positive effect on the retention ratio for all of the four pressures tested $(100,200,300,400 \mathrm{kPa})$. The highest increase in the retention ratio (from $6.1 \%$ to $19 \%$ ) was observed when the pressure was $400 \mathrm{kPa}$.

As the working fluid pressure increased from $100 \mathrm{kPa}$ to $400 \mathrm{kPa}$, so did its retention ratio. An increase in the liquid pressure was accompanied by an increase in the kinetic energy of the drops and a simultaneous decrease in their diameter. Thus, a more even (thin) layer of the liquid was applied to the seed potato peel. The liquid did not drip, which resulted in better retention of the chemical agent on the seed potato surface.

The distance between the sprayer and the seed potato falling path had minimal influence on the amount of the chemical agent left on the seed potato surface. When the liquid pressure was $400 \mathrm{kPa}$, it was $0.6 \mathrm{~g}$ per seed potato. This value was comparable to the amount of the chemical agent left on the seed potato surface after immersion in a liquid, i.e., $0.6 \mathrm{~g}$.

The distance between the sprayer and the seed potato falling path affected the application of the dressing with the electronically controlled valve. When the distance was longer, the amount of the chemical agent left on the seed potato surface decreased. At the same time, the spread between the results presented in the second and third quartiles increased as well.

In all spraying configurations with the electronically controlled valve and an auxiliary airstream there was a greater amount of the liquid left on seed potatoes and greater losses (chemical emissions into the environment) as the working liquid pressure increased. The average loss of the liquid amounted to $8 \mathrm{~g}$ per seed potato when it was applied in a continuous flow from the sprayer. 
The innovative electronically controlled valve with an auxiliary airstream decreased the amount of the chemical agent left on the seed potato surface. When the distance between the sprayer and the seed potato falling path was $50 \mathrm{~mm}$, the amount of the chemical agent decreased by about $30 \%$. At the same time, the loss of the chemical agent emitted into the environment decreased by more than $50 \%$, as compared with the continuous flow of the working liquid from the sprayer.

The auxiliary airstream in the innovative valve significantly influenced the results of the dressing process. The air pressure, or more precisely, the difference in relation to the working liquid pressure had minimal influence on the amount of the chemical agent left on the seed potato surface. When the air pressure was lowered in relation to the working liquid pressure, it significantly affected the amount of the chemical agent lost, i.e., emitted into the environment. The emission was the smallest when the air pressure was $25 \mathrm{kPa}$ lower than the working liquid pressure at 50, 100, $150 \mathrm{~mm}$ distance between the sprayer and the seed potato falling path.

Author Contributions: Conceptualization, Ł.G. and K.K.; methodology, Ł.G.; software, Ł.G.; validation, Ł.G., K.P. and K.K.; formal analysis, K.K.; investigation, Ł.G.; resources, P.M.; data curation, K.K. and K.P.; writing-original draft preparation, Ł.G.; writing — review and editing, K.P. and K.K.; visualization, K.P.; supervision, K.K.; project administration, P.M.; funding acquisition, Ł.G. and K.K. All authors have read and agreed to the published version of the manuscript.

Funding: The authors are grateful for financial support provided by the Poznan University of Technology, Poland, within the framework of fund no 05/51/DSMK/3537.

Conflicts of Interest: The authors declare no conflict of interest.

\section{References}

1. FAO Food and Agriculture Organization of United Nations. Available online: http://faostat.fao.org (accessed on 22 December 2018).

2. Rizvi, S.; Sharma, R.; Srinivas, T.; Manan, A.; Osmanzai, A.; Siddiqui, S.; Wadan, K.; Hakimi, N.; Rahmani, A. Comparative evaluation of local and improved crop varieties through farmers' participation on resource-poor farms in Afghanistan. Acta Agron. Hung. 2012, 60, 11-20. [CrossRef]

3. Serageldin, I. Biotechnology and food security in the 21st century. Science 1999, 285, 387-389. [CrossRef] [PubMed]

4. Farvin, K.H.S.; Surendraraj, A.; Jacobsen, C. Composition and Health Benefits of Potato Peel. Potatoes: Production, Consumption and Health Benefits; Nova Science Publishers: New York, NY, USA, 2012; pp. 196-227.

5. Przybył, K.; Zaborowicz, M.; Koszela, K.; Boniecki, P.; Mueller, W.; Raba, B.; Lewicki, A. Organoleptic Damage Classification of Potatoes with the Use of Image Analysis in Production Process. In Proceedings of the SPIE-The International Society for Optical Engineering, Athens, Greece, 5-6 April 2014; Volume 9159.

6. Przybył, K.; Górna, K.; Wojcieszak, D.; Czekała, W.; Ludwiczak, A.; Przybylak, A.; Boniecki, P.; Koszela, K.; Zaborowicz, M.; Janczak, D.; et al. The Recognition of Potato Varieties Using of Neural Image Analysis Method. In Proceedings of the SPIE-The International Society for Optical Engineering, Los Angeles, CA, USA, 9-10 April 2015; Volume 9631.

7. Camire, M.E. Potatoes and Human Health. In Advances in Potato Chemistry and Technology, 2nd ed.; Elsevier, Academic Press: Cambridge, MA, USA, 2016; ISBN 9780128000021. [CrossRef]

8. Saha, N.K.; Roy, S.K.B.; Kadian, M.S.; Walker, T.; Ilangantileke Lima, S.G.; Verma Patna, V.S.; Central, P.R.S. Potato in rice based cropping systems and analysis of associated constraints: A study in West Bengal, India. J. Indian Potato Assoc. 2005, 29, 18-25.

9. Barnes, M.; Duckett, T.; Cielniak, G.; Stroud, G.; Harper, G. Visual detection of blemishes in potatoes using minimalist boosted classifiers. J. Food Eng. 2010, 98, 339-346. [CrossRef]

10. Przybył, K.; Ryniecki, A.; Niedbała, G.; Mueller, W.; Boniecki, P.; Zaborowicz, M.; Koszela, K.; Kujawa, S.; Kozłowski, R.J. Software Supporting Definition and Extraction of the Quality Parameters of Potatoes by Using Image Analysis. In Proceedings of the SPIE-The International Society for Optical Engineering, Chengu, China, 20-22 May 2016; Volume 10033.

11. Chotkowski, J. Production and Market of Potatoes; Village of Tomorrow Publisher: Warsaw, Poland, 2012; pp. 77-88. 
12. Zimnoch-Guzowska, E.; Chotkowski, J. Potato sector in Poland: From Breeding to Production. In Potato Developments in a Changing Europe; Wageningen Academic Publishers: Noordwijk, The Netherlands, 2006; ISBN 9789086860111.

13. Godier, S.; Rozelot, J.-P. The solar oblateness and its relationship with the structure of the tachocline and of the Sun's subsurface. Astron. Astrophys. 2000, 355, 365-374.

14. Kleinwechter, U.; Gastelo, M.; Ritchie, J.; Nelson, G.; Asseng, S. Simulating cultivar variations in potato yields for contrasting environments. Agric. Syst. 2016. [CrossRef]

15. Van Loon, C.D. Integrated crop management, the basis for environment friendly crop protection of potatoes. Eur. J. Plant Pathol. 1992, 98, 231-240.

16. Lamichhane, J.R.; Messéan, A.; Ricci, P. Research and innovation priorities as defined by the Ecophyto plan to address current crop protection transformation challenges in France. Adv. Agron. 2019. [CrossRef]

17. Kristoffersen, R.; Hansen, A.L.; Munk, L.; Cedergreen, N.; Jørgensen, L.N. Management of beet rust in accordance with IPM principles. Crop Prot. 2018. [CrossRef]

18. Cheke, R.A.; El Hady Sidatt, M. A review of alternatives to fenthion for quelea bird control. Crop Prot. 2019. [CrossRef]

19. Nemecek, T.; Dubois, D.; Huguenin-Elie, O.; Gaillard, G. Life cycle assessment of Swiss farming systems: I. Integrated and organic farming. Agric. Syst. 2011. [CrossRef]

20. Boulard, T. Recent trends in protected cultivations-microclimate studies: A review. Acta Hortic. 2012. [CrossRef]

21. Vernier, F.; Miralles, A.; Pinet, F.; Carluer, N.; Gouy, V.; Molla, G.; Petit, K. EIS Pesticides: An environmental information system to characterize agricultural activities and calculate agro-environmental indicators at embedded watershed scales. Agric. Syst. 2013. [CrossRef]

22. Mahmood, I.; Imadi, S.R.; Shazadi, K.; Gul, A.; Hakeem, K.R. Effects of Pesticides on Environment. In Plant, Soil and Microbes: Volume 1: Implications in Crop Science; Springer International Publishing: Basel, Switzerland, 2016; ISBN 9783319274553.

23. Kempenaar, C.; Been, T.; Booij, J.; van Evert, F.; Michielsen, J.M.; Kocks, C. Advances in Variable Rate Technology Application in Potato in The Netherlands. Potato Res. 2017. [CrossRef]

24. Jonasson, T.; Olsson, K. The influence of glycoalkaloids, chlorogenic acid and sugars on the susceptibility of potato tubers to wireworm. Potato Res. 1994. [CrossRef]

25. Cunha, M.; Carvalho, C.; Marcal, A.R.S. Assessing the ability of image processing software to analyse spray quality on water-sensitive papers used as artificial targets. Biosyst. Eng. 2012. [CrossRef]

26. Ehsani, R.; Sullivan, M.; Walker, J.T.; Zimmerman, T.L. A Method of Evaluating Different Guidance Systems; American Society of Agricultural and Biological Engineers: St. Joseph, MI, USA, 2002.

27. Uno, Y.; Prasher, S.O.; Lacroix, R.; Goel, P.K.; Karimi, Y.; Viau, A.; Patel, R.M. Artificial neural networks to predict corn yield from Compact Airborne Spectrographic Imager data. Comput. Electron. Agric. 2005. [CrossRef]

28. Lyle, G.; Bryan, B.A.; Ostendorf, B. Post-processing methods to eliminate erroneous grain yield measurements: Review and directions for future development. Precis. Agric. 2014. [CrossRef]

29. Ohana-Levi, N.; Bahat, I.; Peeters, A.; Shtein, A.; Netzer, Y.; Cohen, Y.; Ben-Gal, A. A weighted multivariate spatial clustering model to determine irrigation management zones. Comput. Electron. Agric. 2019. [CrossRef]

30. López-Granados, F.; Torres-Sánchez, J.; Serrano-Pérez, A.; de Castro, A.I.; Mesas-Carrascosa, F.J.; Peña, J.M. Early season weed mapping in sunflower using UAV technology: Variability of herbicide treatment maps against weed thresholds. Precis. Agric. 2016. [CrossRef]

31. Metcalfe, H.; Milne, A.E.; Coleman, K.; Murdoch, A.J.; Storkey, J. Modelling the effect of spatially variable soil properties on the distribution of weeds. Ecol. Modell. 2019. [CrossRef] [PubMed]

32. Pedersen, S.M.; Lind, K.M. Precision Agriculture: Technology and Economic Perspectives. In Progress in Precision Agriculture; Springer: Berlin/Heidelberg, Germany, 2017; ISBN 9783319687131.

33. Edwards, G.T.C.; Hinge, J.; Skou-Nielsen, N.; Villa-Henriksen, A.; Sørensen, C.A.G.; Green, O. Route planning evaluation of a prototype optimised infield route planner for neutral material flow agricultural operations. Biosyst. Eng. 2017. [CrossRef]

34. Bauer, A.; Bostrom, A.G.; Ball, J.; Applegate, C.; Cheng, T.; Laycock, S.; Rojas, S.M.; Kirwan, J.; Zhou, J. Combining computer vision and deep learning to enable ultra-scale aerial phenotyping and precision agriculture: A case study of lettuce production. Hortic. Res. 2019. [CrossRef] [PubMed] 
35. Fountas, S.; Sorensen, C.G.; Tsiropoulos, Z.; Cavalaris, C.; Liakos, V.; Gemtos, T. Farm machinery management information system. Comput. Electron. Agric. 2015. [CrossRef]

36. Gierz, Ł.; Gierz, S.Z. Electronically Controlled Mobile Wet Dresser. UPRP PL 226004, 16 December 2016.

37. Gierz, Ł.; Gierz, S.Z. Electronically Controlled Pneumatic-Pressurized Atomizer for Liquids in the Form of a Solution or Suspension. UPRP PL 224859, 14 March 2016.

38. Gierz, S.; Kęska, W.; Gierz, Ł. Electronic Control System for Valves of the Mobile Sorting and Leaning Achine. UPRP PL 223195, 17 December 2015.

39. Erlichowski, T. The Effect of Tuber Treatment with Prestige 290 FS on the Healthiness and Yield of Potato. Available online: https:/www.google.com/url?sa=t\&rct=j\&q=\&esrc=s\&source=web\&cd=1\&ved= 2ahUKEwjL8MWT643mAhUCPFAKHbC0Bg0QFjAAegQIARAC\&url=http\%3A\%2F\%2Fbiblioteka.ihar. edu.pl\%2Fshow_pdf.php\%3Fsrc\%3Dpdf\%2F05\%2Fff5a8e64.pdf\%26name\%3DErlichowski\%2520Tomasz. pdf\&usg=AOvVaw1f65d3erBYnjYk5VfHLzFL (accessed on 12 December 2019).

(C) 2020 by the authors. Licensee MDPI, Basel, Switzerland. This article is an open access article distributed under the terms and conditions of the Creative Commons Attribution (CC BY) license (http://creativecommons.org/licenses/by/4.0/). 